\title{
Endoscopic Management of Obstructive Jaundice in Pregnancy Due to Hepatic Hydatid Disease
}

\author{
Aniruddha Pratap Singh ${ }^{1} \quad$ Shujaath Asif ${ }^{1} \quad$ Sundeep Lakhtakia1,॰ D. Nageshwar Reddy ${ }^{1}$
} 1Department of Medical Gastroenterology, AIG Hospitals,
Gachibowli, Hyderabad, Telangana, India

\begin{abstract}
Address for correspondence Sundeep Lakhtakia, MD, DM, Department of Medical Gastroenterology, AIG Hospitals, Gachibowli, Mindspace Road, Hyderabad, Telangana 500032, India (e-mail: drsundeeplakhtakia@gmail.com).
\end{abstract}
Abstract
Keywords
- pregnancy
- ERCP
- hydatid cyst

Liver is one of the most common site of hydatid infection. Intra-biliary rupture of the hydatid cyst is a common and serious complication that can occur during course of pregnancy. Early diagnosis and treatment as mortality is high due to cholangitis. Surgical treatment is the definitive option, however but in the presence of cholangitis and pregnancy, ERCP with biliary drainage is the preferred management option.
A 24-year-old female primigravida with 6 weeks of gestation age presented with right upper abdominal pain and obstructive jaundice. Ultrasound abdomen showed large cystic lesion in liver with sludge in dilated common bile duct. Computed tomography was not considered due to contraindication from pregnancy. Endoscopic ultrasonography showed echogenic membranes floating in dilated common bile duct. There was minimal intrahepatic biliary radicles dilation. There was a large cystic lesion in caudate lobe $(88 \times 96 \mathrm{~mm})$. There was another adjacent cystic lesion $(43.2 \times 42.3 \mathrm{~mm})$ in left lobe of the liver, close to diaphragm. The cyst showed thick septae (cartwheel appearance) suggestive of hydatid cyst ( - Video $\mathbf{1}$; -Figs. 1 and 2). In view of the first trimester of pregnancy, she underwent endoscopic retrograde cholangiopancreatography (ERCP) without fluoroscopy. Common bile duct was selectively cannulated using sphincterotome and guidewire combination ( $\mathbf{- V i d e o} \mathbf{1}$ ) and bile was aspirated to confirm the position. A wide biliary sphincterotomy was done followed by balloon sweeps using stone retrieval balloon which revealed multiple hydatid membranes. A 7-Fr 7-cm double pigtail biliary stent was placed. She improved symptomatically soon after. A surgical intervention was planned in second trimester. ${ }^{1}$

\section{Video 1}

Cannulation of bile duct. Online content including video sequences viewable at: https://www.thieme-connect. com/products/ejournals/html/10.1055/s-0040-1721656.

Liver is one of the most common site of hydatid infection. ${ }^{2,3}$ It usually presents with pain, vomiting, jaundice, cholangitis, or mass. Hepatic hydatid cyst rupture into the bile ducts (intrabiliary rupture) is the common and serious complication that can occur during course of pregnancy. They can present with fever, severe abdominal pain, cholangitis, pancreatitis, and sepsis. ${ }^{2,3}$ Early diagnosis and treatment are crucial, because it involves two lives (mother and fetus) and mortality is high when it progresses to cholangitis and sepsis. Such circumstance imposes limitations in management options due to risk of abortion, premature labor, and teratogenicity. 4,5

Though the treatment of choice is surgery in intrabiliary rupture of hepatic hydatid cyst, ERCP is useful when there is obstructive jaundice and cholangitis after which elective surgery can be planned.
DOI https://doi.org/ 10.1055/s-0040-1721656 ISSN 0976-5042.
(C2020. Society of Gastrointestinal Endoscopy of India.

This is an open access article published by Thieme under the terms of the Creative Commons Attribution-NonDerivative-NonCommercial-License, permitting copying and reproduction so long as the original work is given appropriate credit. Contents may not be used for commercial purposes, or adapted, remixed, transformed or built upon. (https://creativecommons.org/licenses/by-nc-nd/4.0/).

Thieme Medical and Scientific Publishers Pvt. Ltd. A-12, 2nd Floor, Sector 2, Noida-201301 UP, India 


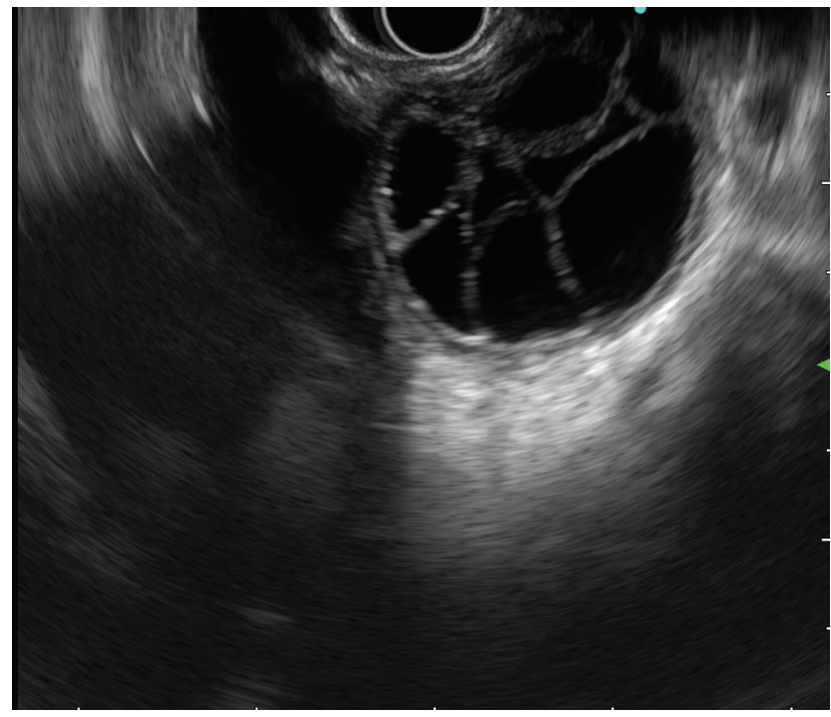

Fig. 1 EUS imaging showing hydatid cyst of liver with classical cartwheel appearance.

\section{Conflict of Interest}

None declared.

\section{References}

1 Rahman MS, Rahman J, Lysikiewicz A. Obstetric and gynaecological presentations of hydatid disease. $\mathrm{Br} \mathrm{J}$ Obstet Gynaecol 1982;89(8):665-670

2 Crow JP, Larry M, Vento EG, Prinz RA. Echinococcal disease of the liver in pregnancy. HPB Surg 1990;2(2):115-119

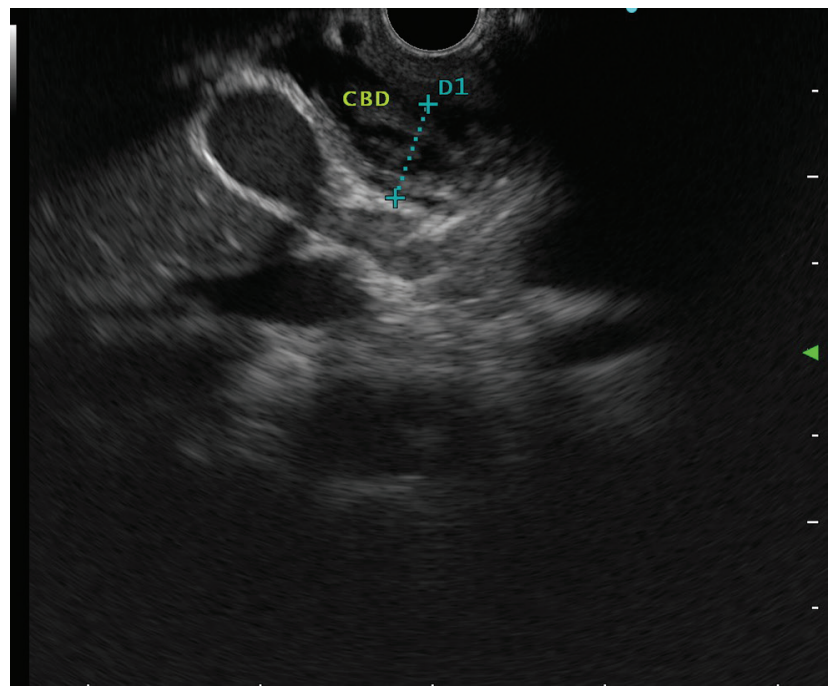

Fig. 2 EUS imaging showing hydatid membranes within the CBD.

3 Haxhimolla HZ, Crowe P. Hydatid disease of the liver in pregnancy. ANZ J Surg 2001;71(11):692-693

4 Cicek B, Parlak E, Disibeyaz S, Oguz D, Cengiz C, Sahin B. Endoscopic therapy of hepatic hydatid cyst disease in preoperative and postoperative settings. Dig Dis Sci 2007;52(4): 931-935

5 Akcakaya A, Ozkan OV, Okan I, Kocaman O, Sahin M. Endoscopic retrograde cholangiopancreatography during pregnancy without radiation. World J Gastroenterol 2009;15(29):3649-3652 